\begin{tabular}{|c|c|c|}
\hline & Int.J.Curr.Microbiol.App.Sci (2021) 10(08): 611-619 & \\
\hline & $\begin{array}{l}\text { International Journal of Current Microbiology and Applied Sciences } \\
\text { ISSN: 2319-7706 Volume } 10 \text { Number } 08 \text { (2021) } \\
\text { Journal homepage: http://www.ijcmas.com }\end{array}$ & 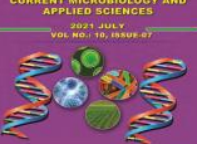 \\
\hline $\begin{array}{l}\text { EXCELLENT } \\
\text { PUBLISHERS }\end{array}$ & & www:ijemas.com \\
\hline
\end{tabular}

\title{
Rainfall Probability Analysis for Crop Planning in Pratapgarh District of Rajasthan, India
}

\author{
R. Subudhi ${ }^{1 *}$, M. S. Kothari ${ }^{1}$ and C. R. Subudhi ${ }^{2}$ \\ ${ }^{1}$ Department of SWE, CTAE, MPUAT, Udaipur-751003, India \\ ${ }^{2}$ Department of SWE, CAET, OUAT, Bhubaneswar-751003, India \\ *Corresponding author
}

Keywords

Rainfall probability,

Crop planning,

Pratapgarh,

Rajastan

Article Info

Accepted:

25 July 2021

Available Online:

10 August 2021

\section{A B S T R A C T}

This study was under taken in the P.G. thesis work in the Dept. Of SWE, CTAE, MPUAT, Udaipur during the year 2021. Pratapgarh district has latitude of $24^{\circ} 03^{\prime \prime} \mathrm{N}$ and longitude of $74^{\circ} 47^{\prime \prime}$ E. From the rainfall analysis, the chance of getting $1215.6 \mathrm{~mm}$ and $912.7 \mathrm{~mm}$ rainfall at $50 \%$ and $75 \%$ probability respectively was found to be in the district with maximum rainfall. The crop selection depends on the areas shown in Iso-probable map for Rajasthan during monsoon months from June to October. At $50 \%$ probability level the crop success is 2 in every 4 years and in $75 \%$ probability level the crop success is 3 in every 4 years.

\section{Introduction}

There is considerable variation in the rainfall pattern throughout the state of Rajasthan. On the basis of rainfall the state has been broadly divided into three main climatic regions: arid or desert region, semi arid region and subhumid region on the basis of rainfall. Pratapgarh district receives highest amount of rainfall in the state. The annual average rainfall at Pratapgarh district was found to be $1378.14 \mathrm{~mm}$. Most of the rainfall occurred during kharif. Thus, this study is proposed to be undertaken with the following objective: Probability analysis of annual, seasonal, monthly and weekly rainfall data of Pratapgarh districts. Many studies are available on the observed trends and variability of rainfall and also extreme rainfall events, but all the studies are based on past 100 years or more data and also the recent years are not included. In the study, 30 years (1989-2019) rainfall data was taken for the probability analysis and crop planning was done using $50-75 \%$ probability level. Thom (1966) employed mixed gamma probability distribution for describing skewed rainfall data and employed approximate solution to nonlinear equations obtained by differentiating log likelihood function with respect to the 
parameters of the distribution. Subsequently, this methodology along with variance ratio test as a goodness- of-fit has been widely employed Kar et al., (2004), Jat et al., (2006), Senapati et al., (2009) applied incomplete gamma probability distribution for rainfall analysis.

In addition to gamma probability distribution, other two-parameter probability distributions (normal, log-normal, Weibull, smallest and largest extreme value), and three-parameter probability distributions (log-normal, gamma, log-logistic and Weibull) have been widely used for studying flood frequency, drought analysis and rainfall probability analysis (Senapati et al., 2009).

Gumbel (1954) and Chow (1964), have applied gamma distribution with two and three parameter, Pearson type-III, extreme value, binomial and Poisson distribution to hydrological data.

\section{Materials and Methods}

The data were collected from www.water.rajasthan.gov.in, for this study. Rainfall data for 30 years from 1990 to 2019 are collected for the presented study to make rainfall forecasting through different methods

\section{Probability Distribution Functions}

For seasonal rainfall analysis of the districts, three seasons- kharif (June-September), rabi (October to January) and summer (February to May) are considered. The data is fed into the Excel spreadsheet, where it is arranged in a chronological order and the Weibull plotting position formula is then applied. The Weibull plotting position formula is given by

$p=\frac{m}{N+1}$

where $m=$ rank number
$N=$ number of years

The recurrence interval is given by

$T=\frac{1}{p}=\frac{N+1}{m}$

The values are then subjected to various probability distribution functions namelynormal, log-normal (2-parameter), log-normal (3-parameter), gamma, generalized extreme value, Weibull, generalized Pareto distribution, Pearson, log-Pearson type-III and Gumbel distribution. Some of the probability distribution functions are described as follows:

\section{Normal Distribution}

The probability density is

$p(x)=(1 / \sigma \sqrt{2 \pi}) e^{-(x-\mu)^{2} / 2 \sigma^{2}}$

where $x$ is the variate, ${ }^{\mu}$ is the mean value of variate and ${ }^{\sigma}$ is the standard deviation. In this distribution, the mean, mode and median are the same. The cumulative probability of a value being equal to or less than $x$ is

$p(x \leq)=1 / \sigma \sqrt{2 \pi} \int_{-\infty}^{x} e^{-(x-\mu)^{2} / 2 \sigma^{2}} d x$

This represents the area under the curve between the variates of ${ }^{-\infty}$ and ${ }^{x}$.

\section{Log-normal (2-parameter) Distribution}

The probability density is

$p(x)=\left(1 / \sigma_{y} e^{y} \sqrt{2 \pi}\right) e^{-\left(y-\mu_{y}\right)^{2} / 2 \sigma_{y}}$

where $y=\ln x$, where $x$ is the variate, ${ }^{\mu} y$ is the mean of $y$ and $\sigma_{y}$ is the standard deviation of $y$. 


\section{Log-normal (3-parameter) distribution}

A random variable $X$ is said to have threeparameter log-normal probability distribution if its probability density function (pdf) is given by:

$f(x)=\left\{\frac{1}{(x-\lambda) \sigma \sqrt{2 \pi}} \exp \left\{-\frac{1}{2}\left(\frac{\log (x-\lambda)-\mu}{\sigma}\right)^{2}\right\}, \lambda<x<\infty, \mu>0, \sigma>0\right\}$

where $\mu, \sigma$ and $\lambda$ are known as location, scale and threshold parameters, respectively.

\section{Pearson Distribution}

The general and basic equation to define the probability density of a Pearson distribution

$p(x)=e \int_{-\infty}^{x} \frac{a+x}{b_{0}+b_{1} x+b_{2} x^{2}} d x$

where ${ }^{a, b_{0}, b_{1} \text { and } b_{2}}$ are constants.

The criteria for determining types of distribution are $\beta_{1}, \beta_{2}$ and $k$ where

$\beta_{1}=\frac{\mu_{3}^{2}}{\mu_{2}^{3}}$

$\beta_{2}=\frac{\mu_{4}}{\mu_{2}^{2}}$

$k=\frac{\beta_{1}\left(\beta_{2}+3\right)^{2}}{4\left(4 \beta_{2}-3 \beta_{1}\right)\left(2 \beta_{2}-3 \beta_{1}-6\right)}$

Where $\mu_{2}, \mu_{3}$ and $\mu_{4}$ are second, third and fourth moments about the mean.

\section{Log-Pearson Type III Distribution}

In this the variate is first transformed into logarithmic form (base 10) and the transformed data is then analyzed. If $X$ is the variate of a random hydrologic series, then the series of $Z$ variates where

$z=\log x$

are first obtained. For this $\mathrm{z}$ series, for any recurrence interval $T$ and the coefficient of skew $C_{s^{p}}$

$\sigma_{z}=$ standard deviation of the $Z$ variate sample $=\sqrt{\sum(z-\bar{z})^{2} /(N-1)}$

And $C_{s}=$ coefficient of skew of variate $Z$

$=\frac{N \sum(z-\bar{z})^{\mathrm{a}}}{(N-1)(N-2) \sigma_{z}^{\mathrm{g}}}$

$\bar{z}=$ mean of $z$ values

$N=$ sample size $=$ number of years of record

Generalized Pareto Distribution

The family of generalized Pareto distributions (GPD) has three parameters $\mu, \sigma$ and $\xi$.

The cumulative distribution function is

$F_{\left(s_{i}, \sigma\right)}(x)=\left\{\begin{array}{cc}1-\left(1+\frac{\xi(x-\mu)}{\sigma}\right)^{\frac{-1}{\xi}} \text { for } \xi \neq 0 \\ 1-\exp \left(-\frac{x-\mu}{\sigma}\right) & \text { for } \xi=0\end{array}\right\}$

for $x \geq \mu$ when $\xi \geq 0$ and $x \leq \mu-\frac{\sigma}{\xi}$ when $\xi<0^{0}$ where ${ }^{\mu \in \mathbb{R}}$ is the location parameter, $\sigma>0$ the scale parameter and $\xi \in \mathbb{R}$ the shape parameter.

The probability density function is 
$f_{(\xi, \mu, \sigma)}(x)=\frac{1}{\sigma}\left(1+\frac{\xi(x-\mu)}{\sigma}\right)^{\left(-\frac{1}{\xi}-1\right)}$

Or

$f_{(\xi, \mu, \sigma)}(x)=\frac{\sigma^{\frac{1}{\xi}}}{(\sigma+\xi(x-\mu))^{\left(\frac{1}{\xi}+1\right)}}$

again, for $x \geq \mu$, and $x \leq \mu-\frac{\sigma}{\xi}$ when $\xi<0$

\section{Results and Discussion}

This study deals with the overall rainfall distributions at different probability level of Pratapgarh district of Rajasthan. Probability distribution enables us to obtain estimates of the probability that certain event may occur, or estimate the variability of occurrence. Selection of a probability distribution which gives the best fit to the observed rainfall enables prediction of design rainfall for a given AEP (Annual exceedence probability), urban infrastructure planning and design of culverts drainage systems etc. In the study $10 \%, 25 \%, 50 \%, 75 \%, 90 \%$ probability analysis of the weekly, monthly, seasonal and annual rainfall was carried out using the Flood software.

The main aim of the study is to suggest reliable crop planning policies for maximum returns to the farmers, development of optimal water allocation policies and management strategies to bridge the gap between water needs and optimal water supply under possible drought conditions in the state.

The probability and frequency of rainfall pattern is one of the important issues for long term planning of agricultural operations, irrigation schemes as well as for the watershed management. The best fit distribution was obtained for Pratapgarh district of Rajasthan considering the least RMSE and mean error values of the distributions obtained in the outcome of the operation which has been carried out in the software.

Pratapgarh district has latitude of $24^{\circ} 03^{\prime \prime} \mathrm{N}$ and a longitude of $74^{\circ} 47^{\prime \prime} \mathrm{E}$. The average rainfall in the district is around $1378.137 \mathrm{~mm}$, most of the rainfall occurred during kharif. The annual rainfall in $50 \%$ probability was found to be $1215.65 \mathrm{~mm}$ for Pratapgarh district of Rajasthan.

During kharif at $50 \%$ probability level, the rainfall is $1120.6 \mathrm{~mm}$ where as only $12.11 \mathrm{~mm}$ and $1.5 \mathrm{~mm}$ was received during rabi and summer respectively. Crops are most sensitive to water deficit during emergence of seedling, flowering and early yield formation and least sensitive to water shortage in late season stage. Crops grown for fresh leaves and fruits are more sensitive than those grown for seed or dry fruits. Selection of crop and area under each crop are based mainly on suitable of climate and availability of other input in crop production. Cost of irrigation system and its management is also considered.

The quantity of water to be supplied on monthly, 10 days or weekly basis was decided. Optimum use of rainfall during crop season and available soil moisture storage from pre season rain and reducing peak requirement in water by shifting sowing dates are some of the other factors which are to be considered for cropping system and water management.

The fig 1 shows graphical representation of rainfall at different probability levels.

In the present study, the parameters of distribution for the different distributions have been estimated by FLOOD-flood frequency analysis software. 
Table.1 Rainfall analysis of Pratapgarh district at different probability levels

\begin{tabular}{|c|c|c|c|c|c|c|c|c|}
\hline \multirow{2}{*}{\begin{tabular}{|c|} 
Annual \\
average/Seasons/M \\
onths/SMW
\end{tabular}} & \multirow{2}{*}{\begin{tabular}{|c|} 
Best fit \\
distributi \\
on
\end{tabular}} & \multirow{2}{*}{$\begin{array}{l}\text { Mean } \\
\text { Error }\end{array}$} & \multicolumn{6}{|c|}{ Rainfall at different probability } \\
\hline & & & RMSE & $90 \%$ & $75 \%$ & $50 \%$ & $25 \%$ & $10 \%$ \\
\hline Annual average & GEV & 0.04 & 0.54 & 709.73 & 912.73 & 1215.65 & 1647.09 & 2213.08 \\
\hline kharif & gev & 0.05 & 0.05 & 515.56 & 807.92 & 1120.63 & 1533.76 & 2058.68 \\
\hline rabi & lognormal & 0.03 & 0.04 & 0 & 0 & 12.11 & 51.67 & 152.65 \\
\hline summer & pareto & 0.05 & 0.07 & 0 & 0 & 1.21 & 10.61 & 20.49 \\
\hline January & - & - & - & - & - & - & - & - \\
\hline February & - & - & - & - & - & - & - & - \\
\hline March & - & - & - & - & - & - & - & - \\
\hline April & - & - & - & - & - & - & - & - \\
\hline May & - & - & - & - & - & - & - & - \\
\hline June & logpearson & 0.05 & 0.05 & 0 & 55.82 & 101.55 & 172.32 & 283.46 \\
\hline July & pareto & 0.05 & 0.06 & 326.59 & 356.44 & 423.28 & 538.95 & 694.66 \\
\hline August & $\log 3$ par & 0.06 & 0.07 & 196.01 & 308.82 & 459.82 & 643.45 & 842.57 \\
\hline September & exponential & 0.06 & 0.07 & 22.71 & 62 & 149.39 & 298.77 & 496.24 \\
\hline October & gamma & 0.05 & 0.07 & 0 & 0 & 0 & 41.75 & 136.35 \\
\hline November & - & - & - & - & - & - & - & - \\
\hline December & - & - & - & - & - & - & - & - \\
\hline SMW 25 & lognormal & 0.04 & 0.05 & 0 & 0 & 13.14 & 43.63 & 112.5 \\
\hline SMW 26 & gev & 0.06 & 0.06 & 0 & 0 & 37.19 & 120.02 & 208.24 \\
\hline SMW 27 & lognormal & 0.04 & 0.05 & 0 & 5.76 & 24.4 & 90.12 & 281.84 \\
\hline SMW 28 & pareto & 0.04 & 0.05 & 5.27 & 33.06 & 94.64 & - & 183.35 \\
\hline SMW 29 & exponential & 0.06 & 0.07 & 3.14 & 34.36 & 103.79 & 222.48 & 379.37 \\
\hline SMW 30 & pareto & 0.02 & 0.03 & 8.57 & 39.85 & 95.39 & 157.85 & 202.44 \\
\hline SMW 31 & logpearson & 0.06 & 0.08 & 0.28 & 4.02 & 20.66 & 82.35 & 256.28 \\
\hline SMW 32 & logpearson & 0.05 & 0.06 & 13.51 & 32.86 & 65.73 & 132.17 & 258.03 \\
\hline SMW 33 & gamma & 0.04 & 0.05 & 1.39 & 22.25 & 77.92 & 184.12 & 351.03 \\
\hline SMW 34 & logpearson & 0.04 & 0.04 & 3.46 & 13.81 & 48.23 & 128.74 & 254.5 \\
\hline SMW 35 & ev 3 & 0.07 & 0.08 & 0 & 0 & 42.27 & 135.08 & 233.08 \\
\hline SMW 36 & pareto & 0.04 & 0.06 & 0 & 2.72 & 43.23 & 102.48 & 164.77 \\
\hline SMW 37 & logpearson & 0.08 & 0.09 & 0 & 0 & 8.04 & 50.66 & 180.16 \\
\hline SMW 38 & ev 3 & 0.07 & 0.08 & 0 & 0 & 0 & 37.6 & 82.84 \\
\hline
\end{tabular}


Fig.1 Rainfall at different probabilities of (a) annual and seasonal (b) monthly and (c) SMW at Pratapgarh District

(a)

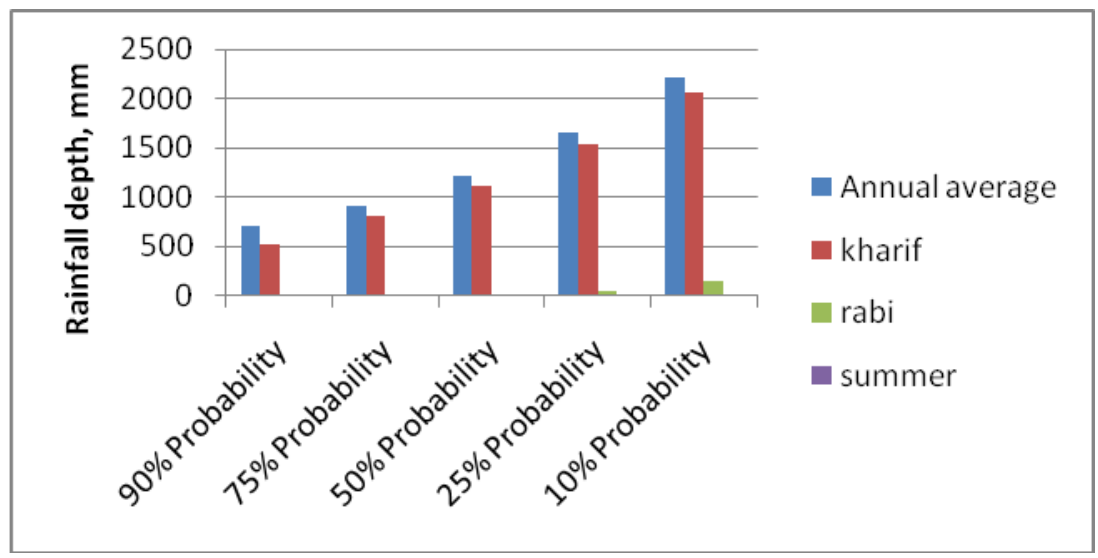

(b)

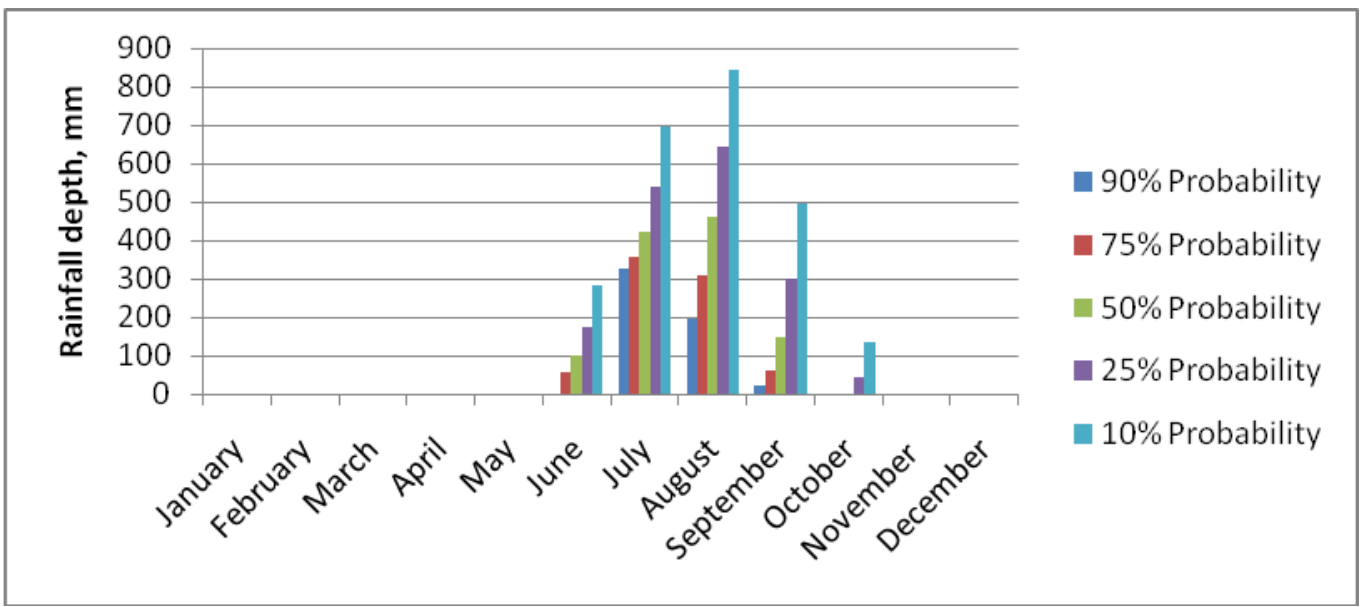

(c)

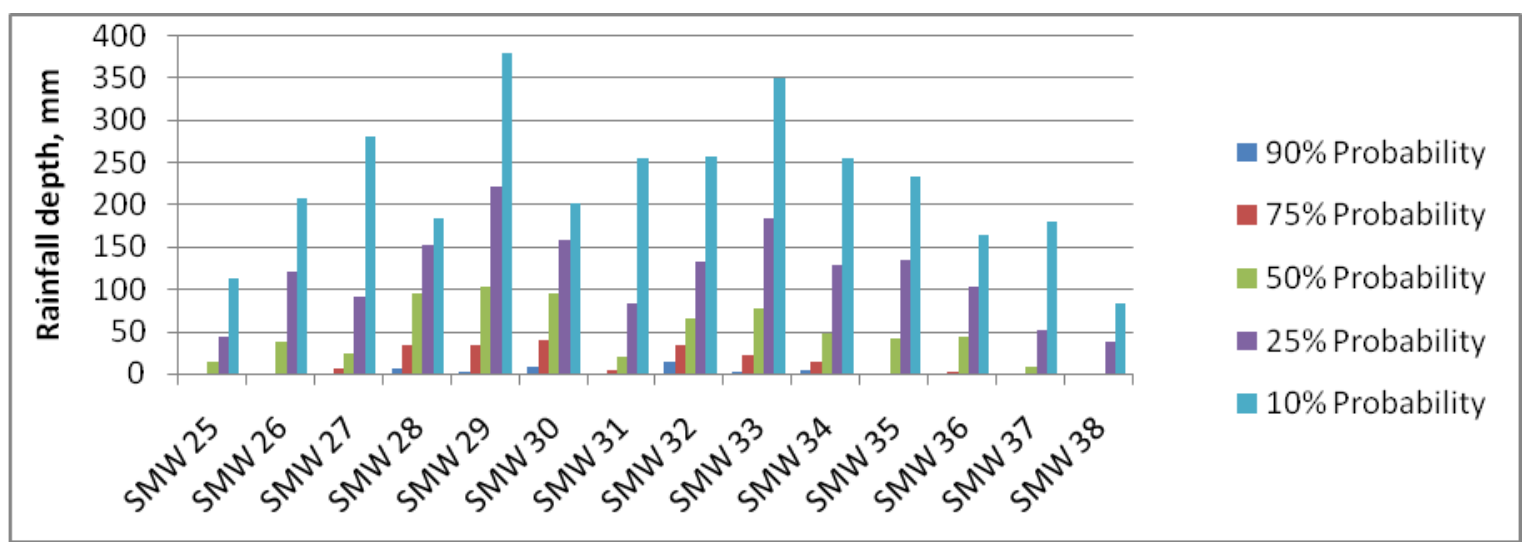


Fig.2 Crop Water Requirement vs. Water availability at 50-75\% probability for pulses and groundnut

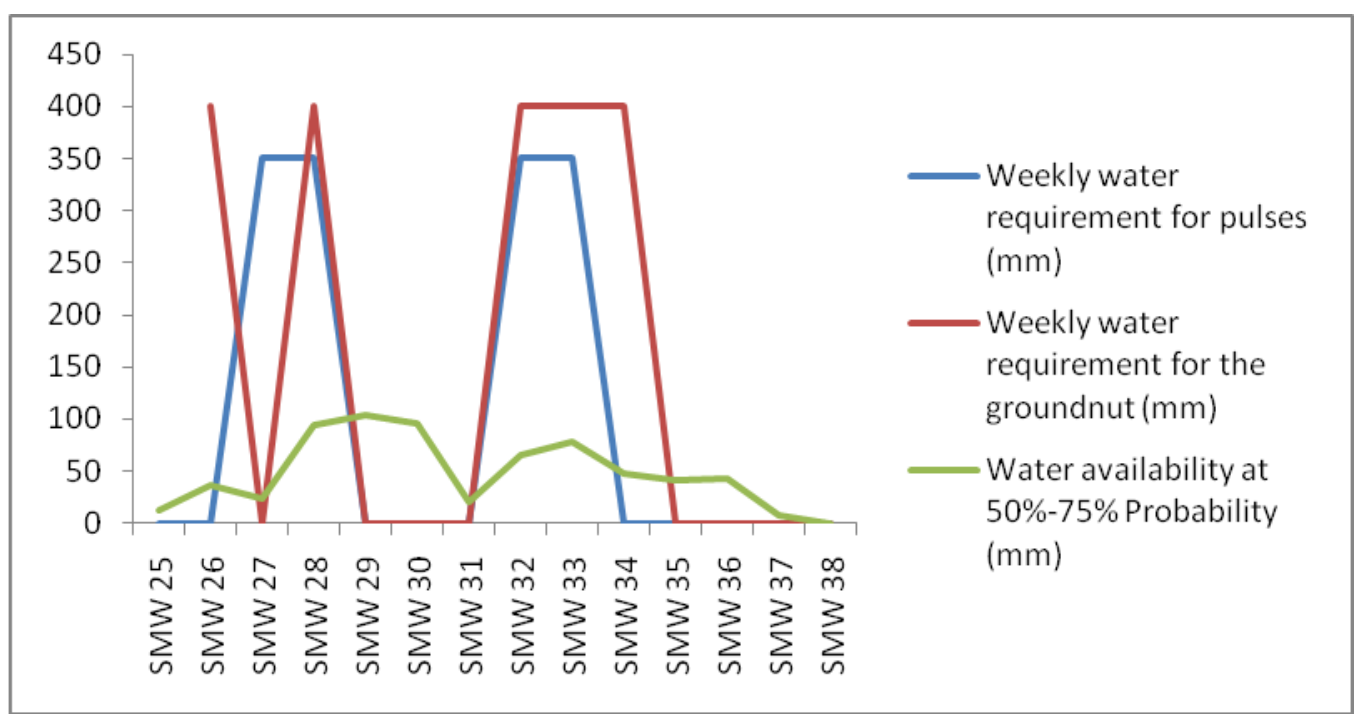

Fig.3 Crop Water Requirement vs. Water availability at 50-75\% probability for wheat and barley

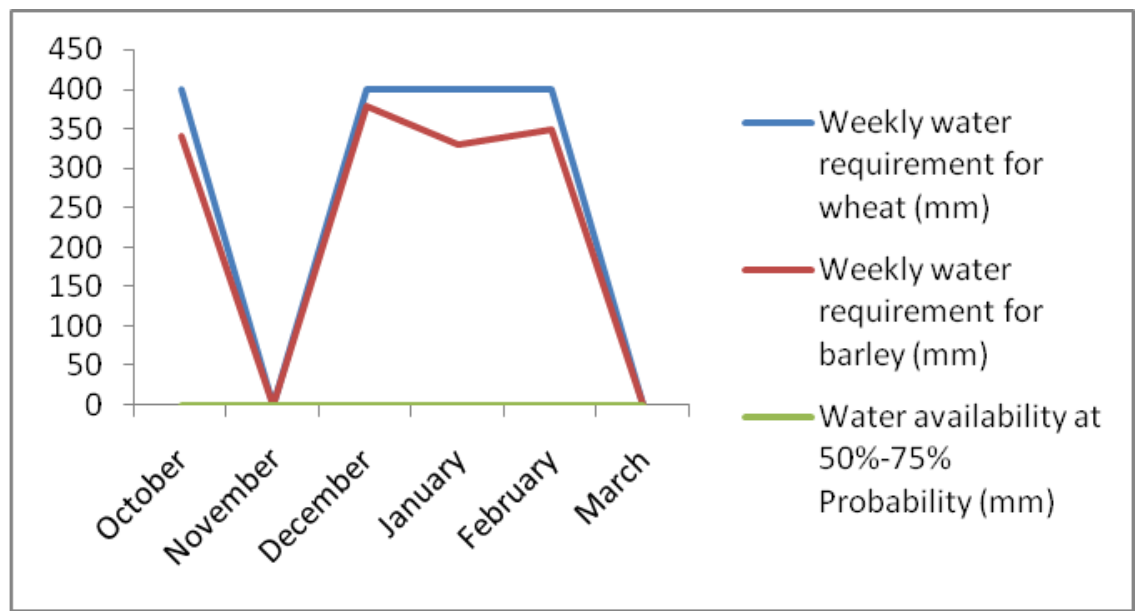

The rainfall data is the input to the software programme. The best fitted distribution of different month and season and annual were presented in Table 1. The annual rainfall at $50 \%$ probability was found to be $1215.65 \mathrm{~mm}$ for Pratapgarh district of Rajasthan. During Kharif at $50 \%$ probability level, the rainfall is $1120.63 \mathrm{~mm}$ where as only $12.11 \mathrm{~mm}$ and $1.11 \mathrm{~mm}$ was received during rabi and summer respectively, so water harvesting structures may be made to grow crops during rabi and summer to utilise the water from the water harvesting structures to increase the cropping intensity of the area. It is also observed that at $75 \%$ probability level the July and August received more than $100 \mathrm{~mm}$.

\section{Selection of crop in $k$ harif}

Mostly pulses are grown in rainfed conditions. In summer, redgram, blackgram, greengram are grown as irrigated crop which need 3 to 4 irrigation at critical stage like germination, flowering and pod formation. Water 
requirement for pulses is around $350 \mathrm{~mm}$ (i.e. after 20-25 days of sowing, podding stage and 50-65 days after sowing, and flowering stage). 4 number of irrigation is provided to the crop. Thus, the water requirement at different time period and the water availability at 50\%-75\% probability rainfall is plotted in the graph below for pulses and groundnut for the selection of better crop for the district and for planning of supplement irrigation and water management.

Due to the low water requirement for pulses as compared to that of groundnut, it is selected as the suitable crop for the district.

\section{Selection of crop in rabi}

Wheat crop requires minimum of 5 irrigations at the following critical stages (i.e. Immediately after sowing, crown root initiation, active tillering stage, flowering stage, grain filling stage;15-20 DAS, 35-40 DAS, 50-55 DAS, 70-75 DAS respectively). Thus, the water requirement at different time period and the water availability at $50 \%-75 \%$ probability rainfall is plotted in the graph below for barley and wheat and for planning of supplement irrigation and water management.

Although weekly water requirement for wheat is slightly more than barley (i.e. by $50 \mathrm{~mm}$ of water), but due to the high local demand of the crop, wheat is selected for the cultivation in the district.

Pratapgarh receives $709.73 \mathrm{~mm}, 912.73 \mathrm{~mm}$, $1215.65 \mathrm{~mm}, 1647.09 \mathrm{~mm}$, and $2213.08 \mathrm{~mm}$ of rainfall at $90 \%, 75 \%, 50 \%, 25 \%$ and $10 \%$ probability level respectively. The district receives highest in state and GEV was found as the best fit distribution. Forecasting of rainfall is essential for proper planning of crop production. In the upland areas suitably redgram, blackgram, greengram can be grown followed by mustard, wheat or gram in rabi season. It is observed that July month gets highest amount of rainfall compared to other months at $75 \%$ probability level. In irrigated area the water harvesting pond may be constructed to harvest kharif water vegetables may be practised by using drip and sprinkler irrigation methods. As per the SMW analysis SMW-25 to 34 are considered wet weeks.

\section{References}

Biswas, B. C. 1990. Forecasting for agricultural application. Mausam. 41(2):329-334.

Chow, V. T. (1964) Hand book of Applied Hydrology McGraw Hill Book Co., NewYork.8-28

Das, M. K. 1992. Analysis of agrometerological data of Bhubaneswar for crop planning. M.Tech. thesis. C.A.E.T., OUAT.

Gumbel, E. J. 1954. Statistical theory of droughts. Proceedings of ASCE. 80(439):1-19

Gumbel, E. J. 1958. Statistics of extremes. Columbia University Press, New York.

Harshfield, D. M. and Kohlar, M. A. 1960. An empirical appraisal of the Gumbel extreme procedure. J. of Geophysics Research, 65:1737-1746.

Kar, G., Singh, R., Verma, H. N. 2004. Alternative cropping strategies for assured and efficient crop production in upland rain fed rice areas of eastern India based on rainfall analysis. 67: 47-62.

Jat, M. L., Singh, R. V., Balyan, J. K., Jain, L. K., Sharma, R. K. 2006. Analysis of weekly rainfall for Sorghum based crop planning in Udaipur region. Indian J. Dry land agric. Res. \& Dev., 21(2):114-122.

Panigrahi, B., 1998. Probability analysis of short duration rainfall for crop planning in coastal Orissa. Indian J. 
Soil Cons., 26(2): 178-182.

Reddy, S. R. 1999. Principles of Agronomy. $1^{\text {st }}$ edition. Kalyani publication.

Sadhab, P. 2002. Study of rainfall distributions and determination of drainage coefficient: A case study for coastal belt of Orissa. M. Tech. thesis. C. A. E. T., OUAT.

Senapati, S. C., Sahu, A. P., Sharma, S. D. 2009. Analysis of meteorological events for crop planning in rain fed uplands. Indian J. Soil Cons., 37(2):85-90

Sharda, V. N. and Das, P. K. 2005. Modeling weekly rainfall data for crop planning in a sub-humid climate of India. Agricultural Management,76:120-138

Subramanya, K. 1990. Engineering Hydrology. $23^{\text {rd }}$ reprint. Tata Mc-graw
Hill Publishing Company Ltd.

Subudhi, C. R. 2007. Probability analysis for prediction of annual maximum daily rainfall of Chakapada block of Kandhamal district of Orissa. Indian J. Soil Cons., 35 (1):84-85.

Subudhi, C. R.; Suryavansi, S. \& Jena, N. (2019) Rainfall probability analysis for crop planning in Anugul block of Anugul district of Hirakud command area of Odisha, India. International Journal of Humanities and Social Sciences.8(3): 49-54.

Thom, H. C. S.1966. Some methods of climatological analysis. WMO Tech. Note. No. 81.

Weibull, W. 1951. A statistical distribution functions of wide applicability. J. Appl. Mech.-Tran. ASME,18(3):293-297.

\section{How to cite this article:}

Subudhi, R., M. S. Kothari and Subudhi, C. R. 2021. Rainfall Probability Analysis for Crop Planning in Pratapgarh District of Rajasthan, India. Int.J.Curr.Microbiol.App.Sci. 10(08): 611619. doi: https://doi.org/10.20546/ijcmas.2021.1008.071 